\title{
ANALYSIS OF COMMON GOVERNANCE TRANSPORT SYSTEM DEVELOPMENT POSSIBILITIES IN THE EAST- WEST TRANSPORT CORRIDOR
}

\author{
Darius Bazaras ${ }^{1}$, Irina Yatskiv ${ }^{2}$, Alminas Mačiulis $^{3}$, Ramūnas Palšaitis $^{4}$ \\ ${ }^{I}$ Transport Engineering Faculty, Vilnius Gediminas Technical University \\ Plytines 27, Vilnius LT-10105, Lithuania \\ Phone: (+370 5)2744776.E-mail: darius.bazaras@vgtu.lt \\ Transport and Telecommunication Institute \\ 2Phone:+(371)-67100594, Fax: +(371)-67100535, E-mail: ivl@tsi.lv \\ ${ }^{3}$ Chancellery of Government \\ Gedimino av. 11, Vilnius LT-01103, Lithuania \\ Phone: (+370 5) 2370635; E-mail: alminas.maciulis@lrv.lt \\ ${ }^{4}$ Transport Engineering Faculty, Vilnius Gediminas Technical University \\ Plytinès 27, Vilnius LT-10105, Lithuania \\ Phone: (+370 5) 2370635; E-mail: ramunas.palsaitis@vgtu.lt
}

\begin{abstract}
Equitable access to efficient economic infrastructure and effective public services is essential to achieving the future economic growth. Insufficient transport infrastructure and long border crossing procedures limiting international accessibility for goods and passengers are the biggest present problems in the East-West transport corridor. The joint action plan must highlight the areas and components of the transport system, which are important for the effective interconnectivity of the individual networks, and/or for absorbing the steadily increasing intraregional and transcontinental freight flows. The successful East-West transport corridor activities' governance first of all needs to identify the corridor's administrative structure, non-governmental organizations' (NGO) place in the management structure, partnerships between the transport hubs in the EWTC mechanism and the possibility of cooperation between private and public sectors.

The latest events and constantly changing environment show that the impact of political solutions on business is prevalent in the CIS and the EU countries. Thus, the analysis of economic, political, managerial, legal, even moral aspects that affect the interests of the stakeholders remain significant.
\end{abstract}

Keywords: transport corridors, management, governance, planning, infrastructure

\section{Introduction}

The majority of the surveys presented in this article were organized and executed by the international project "BSR TransGovernance" activities. This project was financed by the European Union's Baltic Sea Region Programme 2007-2013. The project objective is to demonstrate how multilevel governance models, tools and approaches can contribute to a better alignment of transport policies in the BSR at various administrative levels and better incorporation of the business perspective. This is expected to increase commitment of public and private stakeholders to achieving greener and more efficient transport in the Baltic Sea Region, in line with Priority Area Transport of the EU Baltic Sea Strategy.

The project will place particular focus on developing and testing joint planning and implementation frameworks for transport policies at reference scales, that have witnessed a long process of cooperation across the national borders with involvement of public/private stakeholders, and/or which have gathered a vast evidence for Multi-level governance (MLG) actions. These are: MACRO (overall BSR area), MESO (cross-border integration areas), CORRIDOR (transnational multimodal transport corridors) and MICRO (intermodal terminals).

In specific real conditions at those reference scales the project will employ several demonstration showcases. Through the so called 'stakeholder management process' the project will encourage relevant public and private actors to jointly develop:

- sustainable implementation and management frameworks for macro regional and cross-border strategies, programmes and action plans; that will be tested on the cases of streamlining the results of the BTO and TransBaltic, by using them in the national and regional transport planning processes (MACRO); 
- MLG models for the planning and operation stages of intermodal terminals - and testing them on five different cases in the BSR (MICRO);

- operational MLG model for better freight management in a transnational transport connecting EU with non-EU countries - and testing it on the East West Transport Corridor (CORRIDOR);

- operational MLG model supporting the transformation of a multimodal transport corridor into a regional development axis.

The project has a strong triple-helix partnership from all BSR EU Member States and Norway representing all vertical governance levels. It is supported by PA Transport Coordinators, national transport ministries and several other actors, which will be engaged as reference partners. (http://www.transgovernance.eu/)

There are notable differences that exist between EU countries (Lithuania, Sweden, Denmark, Germany) and other countries located to the East of EU (Belarus, Ukraine, Russia, Kazakhstan, China). The disparity in quality and availability of infrastructure in particular is seen in the East-West connections (backlog of transport infrastructure investments in the East) (Discussion paper "Promoting sustainable...”2013).

The keynote of the development is effective integration of the EU countries and Eastern countries transport sectors into East-West transport corridor service system and transport services market complying with the common criteria for transport development in the corridor (European Union Strategy for the Baltic Sea region 2010).

The government authorities of all countries which are crossed by the EW transport corridor must consolidate the results of complex joint international efforts directed towards specifying the long-term plans for further East-West transport corridor development perspectives (Šakalys 2011). The EW transport corridor's international importance and the priority status must be given at the highest governmental level in all $8-10$ countries whose territories it crosses. The decisions must focus on the better use of the existing infrastructure, "intelligent" management of traffic, networks and systems (Palšaitis, Zvirblis 2010).

Due to the specific nature and needs of the East-West transport corridor countries the region is covered by its own transport network. One of the biggest present problems is insufficient transport infrastructure and long border crossing procedures limiting international accessibility for goods and passengers (Bazaras et al. 2013).

In order to define a mission of the public authorities in the field of transport system development, it is essential to analyse two most important segments of this broad system: the infrastructure and its users (carriers, operators) that have different specific features of functioning and activity development. Transport networks in EW corridor countries are a driving force of common market competitiveness or even markets themselves. (European Union Strategy for the Baltic Sea region. 2010) Therefore, the development and modernization of transport infrastructure and removing the bottlenecks are the essential measures that ensure economic progress in working out national economy development strategies and programmes of both the EU, CIS and other East countries (International project "BSR TransGovernance" 2014).

\section{Transport system development situation in the East-West transport corridor countries}

Three integrated environments can be distinguished when describing the current transport system development situation in the East-West transport corridor countries. Analyses of these environments, that directly affect transportation efficiency and safety (Bazaras, Palšaitis 2011), describe main problems of transportation in each East-West transport corridor country and in the region. The existing transportation management and development organization model of separate East-West transport corridor country is presented in Figure 1. Relations between the elements are shown in Figure 2.

In Figure 2 arrows indicate the links between cells, which show that these environments are interrelated and cannot be distinguished. The largest influence on other elements of the environment has EU, CIS and other East countries and transport system development policy.

Common to all three environmental elements, is the cost of transportation and investment in to the transport system infrastructure development, as well as efficiency and quality of services for customers. The important aspects are the interconnection of individual transport networks of the EU, CIS and other Eastern countries, reduction of infrastructural drawbacks and harmonization of the various transport development priorities. 


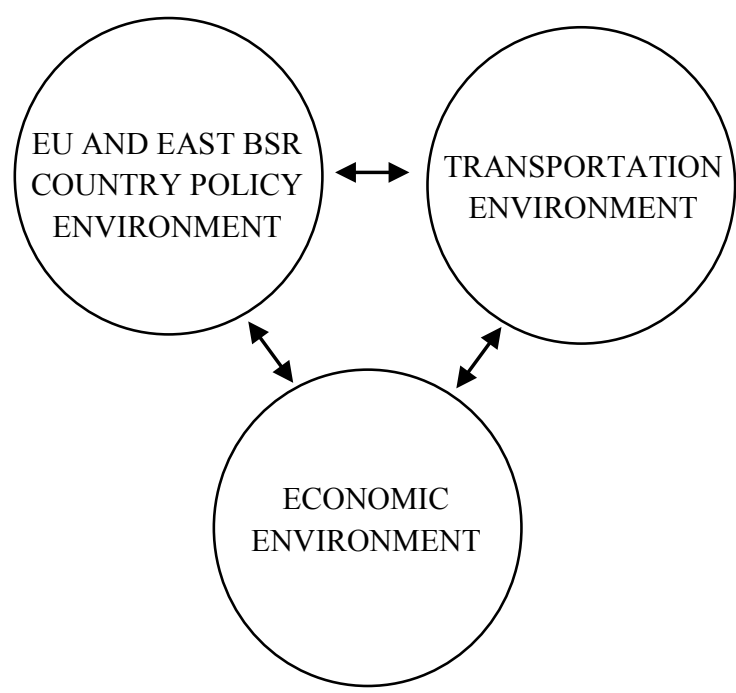

Figure 1. Existing EU, CIS and other East countries transport system organization and development model

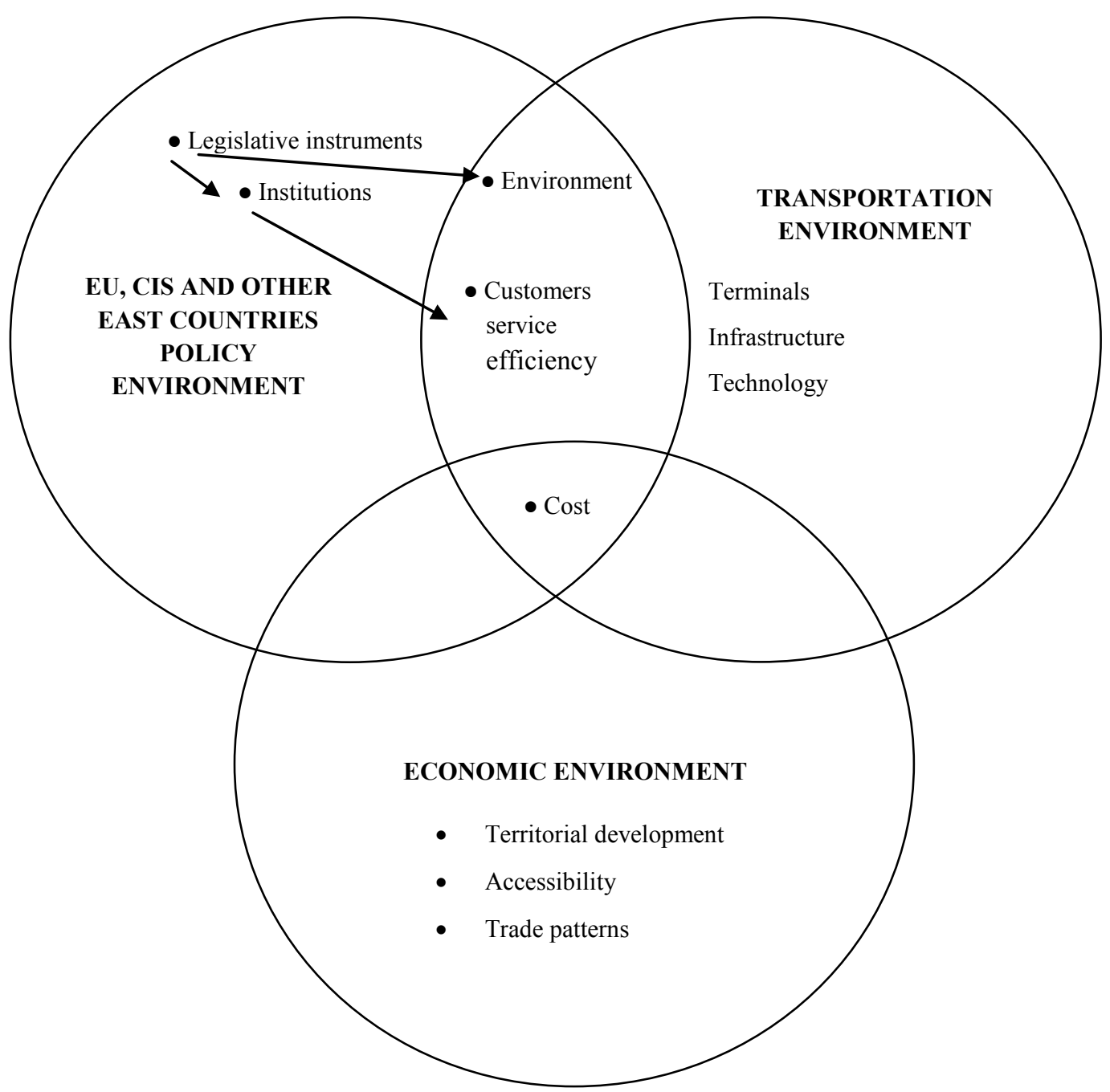

Figure 2. Links between East-West transport corridor countries' transport systems organization and constituent elements of development model 
Supply chains are becoming more and more global and further integration of EU companies with these global value chains can enhance more and more trade gains with third countries that have different specialisation. This can be done by further opening the EU economy to the rest of the world. Bilateral and multilateral free trade agreements (FTAs) would be the best way to reducing trade barriers. They should not only remove international trade tariffs, but also lower barriers beyond the borders (OECD (2014), OECD Surveys: European Union 2014, OECD Publishing. http://dx.doi.org/10.1787/eco_surveys-eur2014-en). The EU already concluded FTAs with some Eastern countries including Georgia and Moldova (as well as Ukraine but with suspension till 2016). On-going FTA negotiations with dynamic Asian economies can yield substantial economic gains and increase trade flows. This requires actions to overcome the impact of administrative borders on efficiency of transport flows within EU, CIS and other Eastern countries and to reduce the remoteness of this area to the main economic centers of Europe and other parts of the world (Sydorowski, Talberg 2013). This also requires better connections between the EU member states and Eastern Partnership countries, Russia, the Black Sea and the Mediterranean regions as well as Far East countries. The joint action plan must highlight the areas and components of the transport system that are important for the effective interconnectivity of the individual networks, and/or for absorbing the steadily increasing intraregional and transcontinental freight flows. A joint strategic transport planning process must support sustainable growth in the EU, CIS and other East countries and requires close cooperation between the European, national, regional authorities, concerned professional associations and involvement of the public and private market stakeholders.

\section{Benefits of EU, CIS, eastern partnership and other eastern countries common transport system development for all stakeholders}

Transport is an integral part of most economic activities. Therefore, adequate transport services provision is a pre-requisite for sound economic development. When traffic volumes are increasing to the point that congestion arises, it is of greatest importance to ensure the accessibility of the major economic centers. This is possible only when there is joint strategic transport planning process and close cooperation between the national authorities and involvement of the market stakeholders. More efficient transport services facilitate trade and widen the geographical space for competition by reducing the cost of delivery, thereby boosting economic growth. This is particulary true in transport corridors and hubs areas of transport system development.

Table 1 contains the expected benefits for the different stakeholders, upon common transport system development.

Table 1. Benefits of East-West transport corridors countries common transport system development

\begin{tabular}{l|l}
\hline \multicolumn{1}{c|}{ STAKEHOLDER } & \multicolumn{1}{c}{ EXPECTED BENEFITS } \\
\hline (Inland) shipping companies & Higher quality of service and entering of new markets \\
\hline Existing shippers & $\begin{array}{l}\text { Lower transport costs, more transport opportunities/alternatives, greater reliability and } \\
\text { safety. }\end{array}$ \\
\hline Potential (new) shippers & $\begin{array}{l}\text { Better access to market, opening up of new markets, more transport opportunities/ } \\
\text { alternatives, lower transport costs. }\end{array}$ \\
\hline Railways & Higher quality of service and possibility to compete with the separate market segments. \\
\hline Road haulage industry & Higher quality of service, greater flexibility and reliability. \\
\hline Forwarding industry & Greater range of transport opportunities/alternatives, lower costs. \\
\hline $\begin{array}{l}\text { Intermodal transport operators } \\
\text { (MTO's) }\end{array}$ & $\begin{array}{l}\text { Better coordination of activities, higher quality of service, more transport alternatives, } \\
\text { lower costs. }\end{array}$ \\
\hline $\begin{array}{l}\text { Authorities, policy makers and the } \\
\text { society at large. }\end{array}$ & $\begin{array}{l}\text { Efficient interfaces between transport networks, need - based approach to infrastructure } \\
\text { investments, additional transport opportunities/alternatives, enabling limitation/ control of } \\
\text { traffic congestion, greening transport corridors. Increased competition, offering cost- } \\
\text { effectiveness (and accelerated introduction of market principles). }\end{array}$ \\
\hline
\end{tabular}

All stakeholders involved in transportation processes can expect to benefit from the common EU, Eastern Partnership, CIS and other Eastern countries transport systems development. It will contribute to a sustainable growth of transport capacity alongside the lesser energy consumption and emissions. 
Common transport system development must be strongly supported by each countrie's national government policy makers especially because of its socio-economic benefits for business and society as a whole. Currently, users of transport systems base their choice of preferred mode or transport on the direct costs only. Common East-West transport corridor transport system development will stimulate intermodal transport development which will be cheaper than the alternatives and will offer better quality of services. Planning and funding of intermodal mobility must be addressed jointly for all transport modes according their respective contribution to ensuring better access.

Therefore it is of crucial importance to interconnect individual transport networks of the EastWest transport corridor countries, diminish infrastructural drawbacks and harmonize various transport modes development priorities. Activities related to planning and developing of the transport networks should be aligned with the regional development perspective. For this matter, the establishment of formalized coordinating bodies (e.g. EGTC or other structures) for the regional transport systems and nodes/hubs connecting East-West transport corridor is essential. Those coordinating bodies should negotiate and identify most prominent bottlenecks and obstacles in transport connections to major European and transnational corridors and aim at identificating the most important investment needs for transport corridors that cross various East-West transport corridor countries (Fastén 2012).

This would allow to bring together a variety of stakeholders at all levels of administration, business and civil society along the corridor and to address specific issues of green corridor development as well as to attract funds for the corridor development and to ensure further East-West corridor planning.

Furthermore, better integration of relevant country's transport markets into the socio-economic development processes of the region is required. Bridging EU, Eastern Partnership, CIS and other Eastern countries transport networks could increase the entire region's accessibility.

\section{Methodology of the survey}

To investigate East West transport corridors strengths and weaknesses with respect to better alignment of transport policies within the EWTC is possible /by using of the Delphi Technique method (Hsu \& Sandford 2007). During the survey the expectations and future visions of different kinds of institutions and companies were determined. The first step of the survey was to choose a heterogeneous target group, in order to guarantee an analysis from as many perspectives as possible. In each country that is crossed by EWTC, from five to ten interview partners were selected, representing different institution or company groups. Another aspect in selecting the companies or institutions was the possibility to contact potential interview partners on a higher management level. The private sector was represented by transport and logistics service providers. The public sector was mainly represented by the administrators responsible for state and regional development. Support initiatives may either belong to the private or the public sector or are public-private-partnership. Both institutional groups have experience in initiating, financing and executing regional development activities. Last, representatives from research institutions completed the target group by an independent and research-oriented perspective.

For the identification directions of multi-level governance to better align transport policies in the East-West transport corridor two round surveys were organized.

The first round survey was performed during the October of 2013. The first distributed questionnaire's task was to find out how joint governance of East-West transport corridor must highlight the areas and components of the BSR transport system that are important for the effective interconnectivity of the individual networks, and/or for absorbing the steadily increasing intraregional and transcontinental freight flows. 50 questionnaires were distributed and 18 questionnaires were received back filled (Germany -2 , Sweden -5 , Lithuania -2 , Ukraine -1 , Russia -1 , China -1 , other countries -6 .)

The second round survey was conducted by web-basis survey system during 18-04-2014-15-052014 time period. Questionnaire was sent to EWTCA members and relevant authorities directly involved in the transport corridor management activities. Number of the respondents was 21. Countries respondents were: Denmark, Germany, Sweden, Norway, Russia, Lithuania. 13 respondents were representing EWTCA members.

\section{Transport corridors management sensitive points}

The survey identified that transport infrastructure in the EWTC is extremely important for effective development of transport services quality, reliability and attractiveness. Greater attention must 
be paid to the corridor's infrastructure in Eastern Partnership and CIS countries (Table 2). However the EWTC transport infrastructure development in EU countries must also be in the centre of all activities.

Table 2. Infrastructure "bottlenecks" in the EU and CIS countries

\begin{tabular}{l|c|c}
\hline \multicolumn{1}{c|}{ Bottlenecks } & EU & EPC/CIS \\
\hline Infrastructure & 6,78 & 7,61 \\
\hline Equipment & 6,22 & 7,33 \\
\hline Services provided using international intermodal transport & 7,61 & 7,67 \\
\hline Conditions for the effectiveness of international intermodal transport services in the corridor & 7,94 & 7,89 \\
\hline
\end{tabular}

It is extremely important to create cooperation system along transport corridor between governmental institutions and private companies (Table 3). The differences in terms of the equipment, legal regulation, information and communication technologies (ICT) and transport and logistics business model usage must be eliminated.

Table 3. Sensitive points in the management of the transport corridors

\begin{tabular}{|c|c|}
\hline Sensitive point & Rate \\
\hline Can be a single moderator for management process organization? & 5,35 \\
\hline Differences in the equipment using. & 6,06 \\
\hline Differences in the transport and logistics business model using. & 6,56 \\
\hline Differences in the legal regulation. & 7,11 \\
\hline Differences in the ICT usage. & 7,29 \\
\hline Cooperation along transport corridor from private companies' point of view. & 7,50 \\
\hline Cooperation along transport corridor from governmental (municipality) institutions point of view. & 7,78 \\
\hline
\end{tabular}

It is crucial to identify the corridor's administrative structure, EWTC association place in the management structure, partnerships between the transport hubs in the EWTC mechanism, as well as cooperation strengthening possibilities between private and public sector for effective the East-West transport corridor activities governance.

As it was previously noticed - research methodology is broad and comprises diverse aspects related to transport corridor management possibilities. However, this article intends to highlight the most problematic points - bottleneck effect and sensitive points in weak management aspects. Additional research results are still processed and will be presented in other publications.

Research results indicated that bottleneck effect is unambiguously evaluated as more problematic phenomenon in the CIS and Eastern Partnership countries than in the EU member states. Virtually all problematic scores in the evaluation were assigned to the CIS and Eastern Partnership countries. This shows that the functioning of infrastructure and related equipment as well as quality of services provided are assessed as more complex and problematic in comparison with the EU member states. The present evaluation indicates that the establishment of general methodology and possible management institutions requires inevitable confrontation with specific problematic points at the particular environment. Therefore, different economic-political circumstances in the CIS/Eastern Partnership countries and the EU area are substantially relevant and theoretically possible equalization of these areas is the matter of the separate scientific discussions.

The other aspects of research were sensitive points in management. This term was coined and provided for the respondents as the prerequisite for the evaluation of possible challenges within unified management of transport corridor. The results were astonishing - the idea of single moderator was evaluated in the frames of the lowest relevance score by the respondents. The explanation of this evaluation may be twofold: 1) respondents did not pay enough attention to establishment of a unified management framework institution; 2) Experts consider the establishment of this single moderator is hardly implementable. However, the following evaluation criteria remain significant due to practical implementation issues - legal regulation; application of ICTs; co-operation between private and public 
sectors. All of the aforementioned criteria are directly linked with management processes and authors assume that they should be coordinated by a unified management framework/institution alongside newly established management technologies which would be admissible to all stakeholders.

Single EU and CIS/ Eastern Partnership countries administrative structure (directorate) has many advantages for transport policy in the development of EWTC. It could:

- Improve and develop regional and local transport infrastructure;

- Promote multimodal transport and intermodality within the EWTC;

- Provide high value added logistics services;

- Ensure sustainability of transport system through energy efficiency and improve mobility demand management;

- Improve traffic safety and security.

In accordance with the conducted research and assessing the problematic transport corridor management aspects it is therefore possible to formulate the following questions linked to the establishment of potential unified management framework/institution. It would be possible to create Single EU and CIS/Eastern Partnership countries administrative structure (directorate) upon finding solutions to these issues:

- Who can be a constitutor?

- What could be the scale of powers allocated?

- What would be the finance source? countries?

- What would be the nature of cooperation with the transport administrations of particular

However, more realistic would be to create the binary EU and CIS/Eastern Partnership and other Eastern countries (including China) administrative structures (directorates) responsible for:

- Transport activities coordination alongside EWTC;

- Improvement and development of the regional and local transport infrastructures;

- Promotion of multimodal transport and intermodality within the EWTC;

- Increasingly make use of ICTs via delivering relevant services on-line;

- Provision with high value added logistics services;

- Ensuring sustainability of transport system through energy efficiency and better mobility demand management;

- Improvement of traffic safety and security.

The binary administrative structure can be created answering the following questions:

- Who can be a constitutor?

- What could be the scale of powers shared?

- What would be the finance sources?

- What could be the nature of cooperation with the transport institutions of particular countries/

The main motivation for establishing a management structure for the development EWTC is the possibility to combine the short term perspective that prevails among the business community with medium and the long term perspective that EWTC Association could add to the corridor in terms of improving its functions and capacity, when needed.

This includes the necessary dialogue with regional, national or the EU important institutions - a dialogue that could not be successfully handled by individual companies.

\section{Critical implementation issues}

During the survey the following elements were considered as being critical implementation issues that would need to be addressed at the next stage of the East-West transport corridor development strategy and programme:

- Organizational structure, governance arrangements and reporting structures. The East-West transport corridor Steering Committee nominates and establishes the East-West Transport Corridor steering group and East-West Transport Corridor programme organization teams, as well as the two independent review groups.

- Financing options. Integrated programme organisation teams develops the financing and funding scheme and presents it to the East-West Transport Corridor steering group and the East-West transport corridor States and other countries administrative units for the confirmation. 
- Implementation of programme risk management strategy. The East-West Transport Corridor programme organization team develops the Risk Management Plan and presents it to the East-West Transport Corridor steering group and EWTC countries administrative units for approval.

- Resource planning with particular reference to the early identification of long lead items. The East-West Transport Corridor programme organization team develops a resource based critical path implementation programme for review and acceptance by the PSG and follows with a staffing plan for internal resources and external consultancies.

- Implementation of robust and effective stakeholder consultation programmes at all stages of the process. The East-West Transport Corridor programme organization and East-West Transport Corridor steering groups approve the involvement of a public-relations consultant to assist in establishing the necessary public relations campaign for the programme.

- Integration strategies with existing rail systems throughout the EWTC. The East-West Transport Corridor programme organization team performs a system-wide audit of all existing systems and planned improvements that is considered as a country input into the Options Assessment plan.

- Impact assessment of programme on regional transport market provision and competing modes; The East-West Transport Corridor programme organization team conducts, in cooperation with external consultants, a detailed transport market analysis to further justify the transportation models developed during the feasibility study.

- Identification and consultation on programme phasing requirements noting commercial, social and political imperatives. The East-West Transport Corridor programme organization team shall enhance the critical path implementation programme with required interfaces at the national, regional and municipal levels to streamline the planning, land expropriation and design approvals processes.

\section{Summary}

The joint action plan must highlight the areas and components of the transport system which are important for the effective interconnectivity of the individual networks, and/or for absorbing the steadily increasing intraregional and transcontinental freight flows. The following elements are considered as critical implementation issues and would need to be addressed at the next stage of the East-West transport corridor development programme:

- output definition (organizational structure, potential financing scheme, risk management overview, pre-planning budget, pre-planning time-line, etc.);

- organisational structure, governance arrangements and reporting structures;

- financing options and resource planning;

- implementation of programme risk management strategies;

- integration strategies with existing rail systems throughout the EWTC system;

- impact assessment of programme on regional transport market provision and competing modes;

- identification and consultation on programme phasing requirements noting commercial, social and political imperatives.

In general, it is notable, that transport corridor management mechanism still remains problematic, firstly due to economic and political environment that influences business organization and regulatory models. The latest events and constantly changing environment show that the impact of political solutions on business is prevalent in the CIS/Eastern Partnership countries and the EU countries. Thus, the analysis of the following aspects remains significant: economic, political, managerial, legal, even moral affecting the interests of the stakeholders.

The unified administrative structure of the East-West transport corridor has a great number of advantages; however, experts consider that it is hardly implementable.

\section{References}

1. European Union Strategy for the Baltic Sea region and the role of macro-regions in the future Cohesion policy. (2010) Draft report by MEP Wojciech Olejiczak. Committee of Region Development European Parliament. 4.2.2010.

2. Discussion paper Promoting sustainable transport and removing bottlenecks in key network infrastructures. Thematic Programming Workshop. 24 April, 2013, Riga. 9 p.

3. Bazaras, D., Bartulis, V., Batarliene, N., Palšaitis, R. (2013) Governance of East BSR countries common transport system development. Reliability and statistics in transportation and 
communication (RelStat'13): proceedings of the 13th international conference, 16-19 October, 2013, Riga, Latvia. Riga: Transport and Telecommunication Institute, 2013. ISBN 9789984818580. p. $48-51$.

4. Bazaras, D., Palšaitis, R. (2011) The Impact of the Market Structure on Safety and security in the BSR: Lithuania Point of View. Proceedings of the 11th Reliability and Statistics in Transportation and Communication. (RelStat'11) 173-175 p. 2011 Riga, Latvia. ISBN 978-9984-818-46-7.

5. International project "BSR TransGovernance". Information about project. http://www.transgovernance.eu/transgovernance/about-the-project.aspx.

6. Fastén.G. Green Corridor Manual. NetPort. Karlshamn. 2012. 98 p.

7. Palšaitis, R., Zvirblis, A. (2010) Multicriteria Assesment of the International Environment to the Lithuania Transport System for Transit Transport. Transport Means 2010. 85-88 p. Proceedings of the 14th International conference. Kaunas. 2010. ISSN 1822-296 X.

8. Chia-Chien Hsu, Brian A. Sandford. (2007) Delphi Technique. Practical Assessment, Research \& Evaluation, 12(10), 1-8.

9. Šakalys, A. (2011) The East-West Transport Corridor Association aims to develop an important logistical link. A platform for efficiency. Innovation Europe. Journal of UK. 2011, 83 p. ISBN 1900521-84-9.

10. Sydorowski, W., Talberg, O. (2013) Multi-level governance-European experience and key success factors for transport corridors and transborder integration areas. Final draft task 3.2. BSR TransGovernance project.

11. TransBaltic Policy Report 2011. 55 p. ISBN 978-91-980129-0-3. www.transbaltic.eu. 